Article

\title{
Optimization of Microwave-Assisted Extraction of Antioxidants from Bamboo Shoots of Phyllostachys pubescens
}

\author{
Gualtiero Milani ${ }^{1}$, Francesca Curci ${ }^{1}$, Maria Maddalena Cavalluzzi ${ }^{1, *}$, Pasquale Crupi ${ }^{2}$,

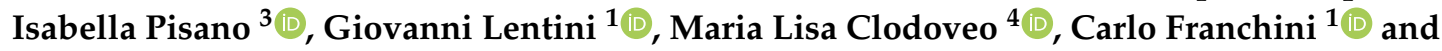 \\ Filomena Corbo ${ }^{1}$ (D)
}

1 Department of Pharmacy-Pharmaceutical Sciences, University Aldo Moro-Bari, Via Orabona, 4, 70126 Bari, Italy; gualtiero.milani@uniba.it (G.M.); francesca.curci@uniba.it (F.C.); giovanni.lentini@uniba.it (G.L.); carlo.franchini@uniba.it (C.F.); filomena.corbo@uniba.it (F.C.)

2 CREA-VE, Council for Agricultural Research and Economics-Research Centre for Viticulture and Enology, Via Casamassima, 148, 70010 Turi, Italy; pasquale.crupi@crea.gov.it

3 Department of Bioscience, Biotechnology and Biopharmaceutics, University of Bari, Via Orabona, 4, 70125 Bari, Italy; isabella.pisano@uniba.it

4 Interdisciplinary Department of Medicine, University of Bari, Piazza Giulio Cesare, 11, 70124 Bari, Italy; marialisa.clodoveo@uniba.it

* Correspondence: mariamaddalena.cavalluzzi@uniba.it; Tel.: +39-080-5442736

Academic Editors: Gianni Sacchetti and Giancarlo Cravotto

Received: 4 December 2019; Accepted: 3 January 2020; Published: 5 January 2020

\begin{abstract}
Bamboo is a well-known medicinal plant in Southeast Asia that recently has attracted attention for its high polyphenol content and its medical and nutraceutical applications. In this work, polyphenols have been recovered for the first time by microwave-assisted extraction (MAE) from an unusual Italian cultivar of Phyllostachys pubescens bamboo shoots. The effects of three independent variables, such as extraction time, temperature, and solid/liquid ratio, on polyphenol recovery yield were investigated and successfully optimized through the response surface methodology. We demonstrated that MAE is an excellent polyphenols extraction technique from bamboo shoots because the total phenolic content obtained under microwave irradiation optimal conditions (4 min at $105^{\circ} \mathrm{C}$ with $6.25 \mathrm{mg} / \mathrm{mL}$ ratio) was about eight-fold higher than that obtained with the conventional extraction method. Furthermore, higher total flavonoid content was also obtained under MAE. Consistent with these results, MAE enhanced the extract antioxidant properties with significant improved DPPH, ABTS, and FRAP scavenging ability. Therefore, this innovative extraction process enhances the recovery of biologically active compounds from Phyllostachys pubescens bamboo shoots with a dramatic reduction of time and energy consumption, which paves the way for its industrial application in functional food production.
\end{abstract}

Keywords: bamboo; microwave-assisted extraction; Folin-Ciocalteu; antioxidant activity; design of experiments

\section{Introduction}

Bamboo is a perennial, woody grass, evergreen plant, and one of the oldest plants on Earth. Although more than 1250 species belonging to 75 genera are distributed worldwide, it grows predominantly in Asia [1,2]. Bamboo is popularly known for its industrial uses and has long been used in China and Southeast Asia both as a food and in traditional medicine [3]. In fact, several pharmacological properties have been reported for bamboo such as anticancer, antioxidant, antibacterial, antidiabetic, antiulcer, anti-inflammatory, and antihypertensive activities [2,4]. Angiotensin-converting enzyme 
inhibition activity has also been recently proposed [5]. Although most research studies have investigated the functional activities of bamboo leaves [6-16], only a few studies have been reported on the functional properties of bamboo shoots, which rank among the five most popular healthcare foods in the world. They are not only delicious but also rich in some nutrient components, such as vitamins, proteins, carbohydrates, and minerals. However, on the other hand, they have low fat content $[1,3,17,18]$.

In particular, they show high content of secondary metabolites-such as phenolic compounds, flavones, and glycosides-which play a pivotal role in providing protection against many chronic and degenerative diseases $[19,20]$. Among them, phenolic compounds, which are commonly referred to as polyphenols, have been reported to be responsible for the antioxidant and anti-inflammatory activities of bamboo shoot extracts [5,21-23]. In fact, it is well known that polyphenols are involved in the redox balance [19] as in the regulation of immune responses [24] of the cells. These features make polyphenols a potentially interesting material for the development of functional foods [25]. Recently, Park et al., reported on the phenolic compound composition and antioxidant activity of different extracts of Phyllostachis pubescens shoots [5]. It is the major species of bamboo in Japan, China, and Korea, belonging to the family Poaceae (or Gramineae) and subfamily Bambusoideae [26]. Since conventional extraction methods, such as that used by Park et al., require long extraction times [27], we decided to optimize the extraction procedure applying a novel extraction technology. Among the innovative technologies, microwave-assisted extraction (MAE) has gained more attention in the past decade due to its advantages such as shortened extraction time, reduced solvent consumption, higher extraction rate, and lower energy consumption $[28,29]$. Moreover, the high reproducibility as well as the controlled temperature and pressure are considered strengths of MAE, which has been extensively used to secondary metabolite extraction from different plant matrices [30-32]. Thus, we chose this approach not only for the many advantages it offers but also because no one had ever been investigated before the effects of microwaves on the polyphenol extraction from bamboo shoots of Phyllostachys pubescens. In particular, an unusual Italian cultivar of Phyllostachys pubescens has been used for the first time with the aim of evaluating the possibility of extraordinarily promoting the cultivation of this plant in the Italian country. Our goal was to demonstrate that microwave irradiation was able to enhance the polyphenol content of bamboo shoot extracts, which perform better with respect to conventional solid-liquid extraction. It is well known that microwave irradiation aids plant matrix disruption and, together with a high temperature extraction that reduces the solvent viscosity, allows for greater recovery of polyphenols and flavonoids. On the other hand, shorter extraction time, in turn, reduces the risk of decomposition and oxidation of phytochemicals, which often ensures high TPC values [33].

Since many parameters could affect the MAE process, it would be advisable to use a statistical technique for quickly optimizing the extraction procedure. Therefore, we used the response surface methodology (RSM) to analyze the influence of many parameters simultaneously as well as their interactions on the response so that the optimal experimental conditions can be readily and confidently established. Extraction time, temperature, and the solid/liquid ratio $(\mathrm{mg} / \mathrm{mL})$ have been chosen as variables to be optimized so as to obtain the highest phenolic recovery. Furthermore, the flavonoid content and antioxidant activity of the extracts obtained from both conventional and optimized microwave-assisted procedures were also evaluated.

\section{Results}

\subsection{Conventional Extraction Procedure}

At first, we performed the bamboo shoot conventional extraction, according to the procedure recently proposed by Park et al. [5], which maintains the same relationship between the bamboo shoots and solvent $(50 \mathrm{mg} / 7.5 \mathrm{~mL})$. In these conditions, we obtained $11.2 \pm 0.1 \mathrm{mg} \mathrm{GAE} / \mathrm{g}$ of bamboo shoots as a TPC value. Having planned to improve the polyphenol extraction with the aid of microwave irradiation, it notoriously allows reducing the solvent consumption. We decided to use $2 \mathrm{~mL}$ as the starting volume in the next MAE (see Supplementary Material). However, it was necessary to first carry 
out the conventional extraction in the same volume $(50 \mathrm{mg} / 2 \mathrm{~mL})$ to, hereafter, compare conventional results and MAE results. Having observed a low reduction in the TPC (6.6 $\pm 0.1 \mathrm{mg}$ GAE/g of bamboo shoots), and hoping to significantly increase it with the aid of RSM, these conditions represented our starting point for the next MAE.

\subsection{Optimization of the Phenolic Extraction Yield under MAE by RSM}

Among the most widely used solvents for extracting phenolic substances, we first chose methanol according to the procedure proposed by Park et al. [5]. Our goal was to enhance their conventional phenolic extraction yield by taking advantage of the use of microwave irradiation, without further modifying their experimental conditions.

The MAE processing conditions selected as independent variables of the experimental design aimed at increasing the extraction of polyphenols from bamboo shoots (Phyllostachys pubescens) were extraction time $(5-10 \mathrm{~min})$, temperature $\left(58-68{ }^{\circ} \mathrm{C}\right)$, and solid/liquid ratio $(12.5-25 \mathrm{mg} / \mathrm{mL})$. This preliminary study showed that higher temperature and both lower concentration and extraction time were necessary to optimize our extraction process (see Supplementary Material). Therefore, RSM was applied for modelling and predicting total phenolic content (TPC) yield and, according to the CCF (central composite face-centered) design, 17 runs were performed for the optimization of the three chosen parameters. The design matrix and the corresponding response values (TPC) were listed in Table 1.

Table 1. Optimization of microwave-assisted extraction of bamboo shoots using response surface methodology: central composite face-centered (CCF) design matrix and observed responses.

\begin{tabular}{ccccc}
\hline Experiment No. & Extraction Temperature $\left({ }^{\circ} \mathbf{C}\right)$ & Solid/Liquid Ratio $(\mathbf{m g} / \mathbf{m L})$ & Extraction Time $(\mathbf{m i n})$ & TPC $^{\mathbf{a}}$ \\
\hline 1 & 75 & 6.25 & 3 & 0.946 \\
2 & 95 & 6.25 & 3 & 1.423 \\
3 & 75 & 10 & 3 & 0.796 \\
4 & 95 & 10 & 3 & 1.239 \\
5 & 75 & 6.25 & 5 & 0.910 \\
6 & 95 & 6.25 & 5 & 1.467 \\
7 & 75 & 10 & 5 & 0.807 \\
8 & 95 & 10 & 5 & 1.479 \\
9 & 75 & 8.12 & 4 & 0.970 \\
10 & 95 & 8.12 & 4 & 1.009 \\
11 & 85 & 6.25 & 4 & 0.947 \\
12 & 85 & 10 & 4 & 0.578 \\
13 & 85 & 8.12 & 3 & 0.769 \\
14 & 85 & 8.12 & 5 & 0.754 \\
15 & 85 & 8.12 & 4 & 0.733 \\
17 & 85 & 8.12 & 4 & 0.761 \\
& 85 & 8.12 & 4 & 0.790 \\
\hline
\end{tabular}

${ }^{a}$ expressed as mg GAE in the total extraction volume.

The quadratic equation derived for TPC is given in Equation (1).

$$
\begin{gathered}
Y=0.781163+0.264907 X_{1}-0.0794 X_{2}+0.0244 X_{3}+0.424 X_{1}^{2}-0.033535 X_{2}^{2}-0.034535 X_{3}^{2}+ \\
0.010125 X_{1} X_{2}+0.038625 X_{1} X_{3}+0.030375 X_{2} X_{3}
\end{gathered}
$$

where $X_{1}$ is the extraction temperature, $X_{2}$ is the solid/liquid ratio, and $X_{3}$ is the extraction time.

It is evident that the response value was mostly affected by the extraction temperature $\left(X_{1}\right)$ as shown by the linear and quadratic terms of the equation. To a lesser extent, the liquid/solid ratio $\left(X_{2}\right)$ also affected the response value. The extraction time $\left(X_{3}\right)$ is almost irrelevant. The results suggest that the change of extraction temperature had highly significant effects on the yield of polyphenols $(p<$ 0.0001) from the bamboo shoots of Phyllostachys pubescens under microwave irradiation.

By the analysis of variance (ANOVA) of a simpler second-order polynomial regression model obtained by omitting insignificant terms, the value of the determination coefficient $\left(\mathrm{R}^{2}\right)$ and adjusted 
determination coefficient $\left(\mathrm{R}^{2}\right.$ Adj $)$ were 0.943 and 0.929 , respectively, which suggests good agreement between the observed and predicted values. Furthermore, the high value of cross-validated determination coefficients $\left(Q^{2}=0.883\right)$ indicated a good predictive power of the model. On the other hand, the regression model was statistically relevant, with a significance level lower than 0.0001 $(p<0.0001)$, and had no significant lack of fit $(p=0.112)$. Taken together, these results confirm that a well-fitting model has been obtained.

Three-dimensional response surface plots, generated by the model, and reported in Figure 1, indicated the effect of each variable on the polyphenol yield (TPC). For the sake of clarity, two variables were represented within the surface plot experimental plane while the other was kept constant at its center level.
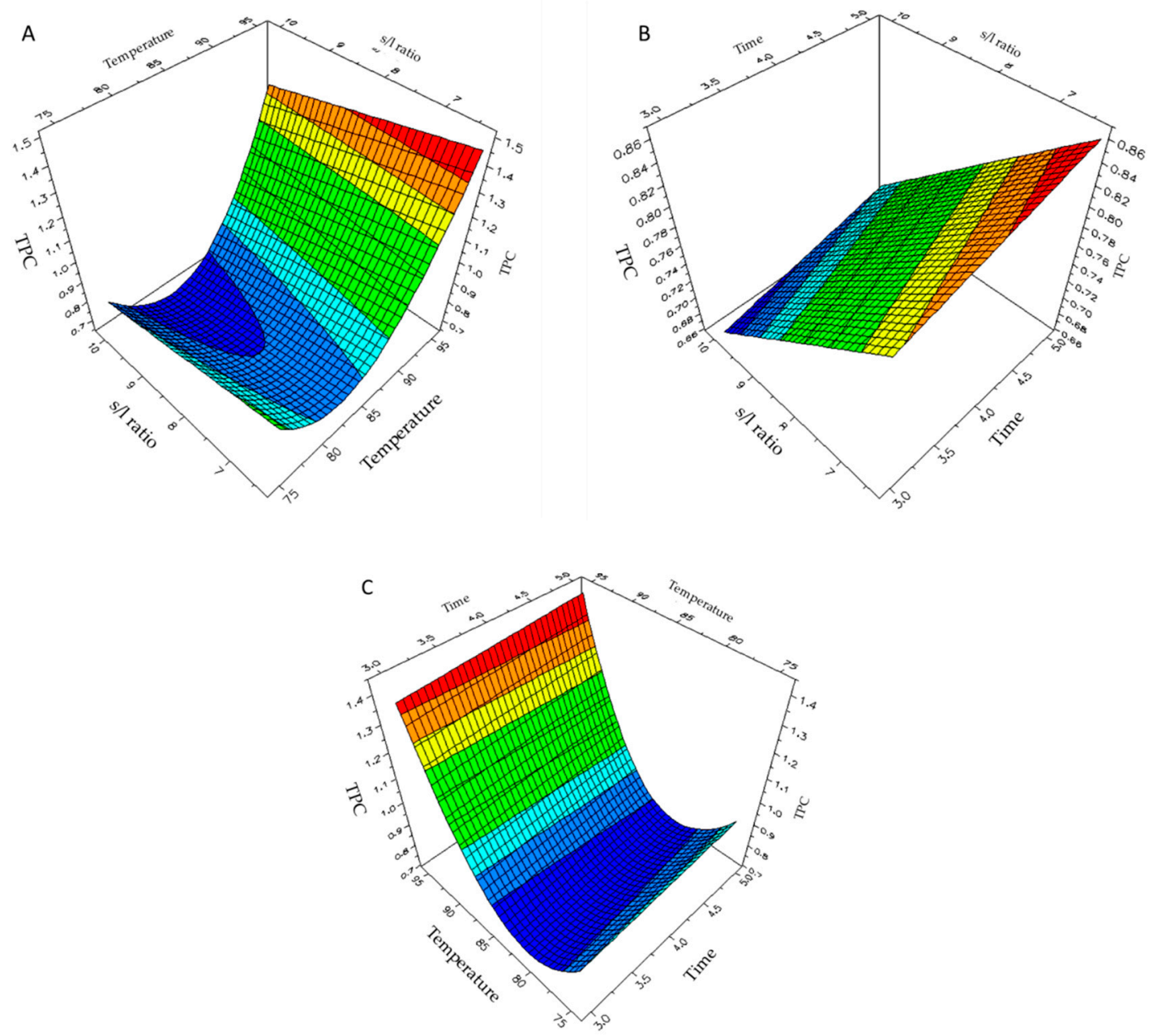

Figure 1. Response surface plots of the effect of (A) solid/liquid ratio and extraction temperature, (B) solid/liquid ratio and extraction time, (C) extraction temperature and time on polyphenol yield (TPC) obtained through MAE.

An increase in the extraction temperature (see Figure $1 \mathrm{~A}, \mathrm{C}$ ) and a concomitant reduction of sample concentration (see Figure 1A) enhanced the extraction yield. As expected from the equation coefficients, extraction time did not strongly affect the response variable and it was almost irrelevant, in the selected range of 3-5 min, compared to the extraction temperature (see Figure 1C).

The found temperature influence is in agreement with the well-known improvement of extraction yield in MAE attributed to microwave heating that occurs by both dipolar polarization and ionic conduction, which are typical of polar and polarizable substances. In fact, as a result of dipole rotation of molecules, hydrogen bonds are broken and the solvent diffusion into the matrix is considerably 
improved, with the extraction yield being enhanced [34]. The water present or the solvent penetrated into plant cells absorb microwave energy, which causes an internal superheating. This can disrupt membrane cells, which facilitates leaching out of the active constituents into the solvent and improving the polyphenol recovery [35]. This phenomenon is greater when the extraction is carried out with solvents with higher heating efficiency under the microwave (higher tan $\delta$ value), as for $\mathrm{MeOH}$ [36]. On the other hand, prolonged extraction time at high temperatures could cause the degradation or oxidation of thermolabile phytochemicals [37], which can be avoided through the shorter extraction time guaranteed by MAE. According to this knowledge, when RSM was applied to bamboo shoots, MAE indicated a particularly short extraction time of just $4 \mathrm{~min}$, which supports the validity of our model. Based on the results presented in Table 1, we can state that higher temperature applied for only a few minutes exerted a significantly positive influence on the amounts of TPC extracted using MAE, even though more in-depth studies are needed to ascertain that there has been no degradation of the biologically-active compounds.

Based on the RSM obtained results, the values predicted by the software as the optimal conditions under microwave irradiation were: $6.25 \mathrm{mg} / \mathrm{mL}$ under microwave irradiation for $4 \mathrm{~min}$ at $105^{\circ} \mathrm{C}$ and the predicted TPC was $2.9 \pm 0.3 \mathrm{mg}$ gallic acid equivalent (GAE). Under these conditions, the experimental value was $2.74 \pm 0.08 \mathrm{mg}$ of GAE (corresponding to $54.8 \pm 1.6 \mathrm{mg}$ GAE/g dry weight, entry 3-Table 2), which is much higher than that obtained for both the conventional extracts, regardless of the solvent volume used [7.5 mL (entry 1-Table 2) or $2 \mathrm{~mL}$ (entry 2-Table 2) for $50 \mathrm{mg}$ of bamboo shoots]. Hence, we can state that the MAE under optimal conditions allowed us to optimize the extraction process proposed by Park et al. [5].

Table 2. Total phenolic, flavonoid contents, and antioxidant activity of bamboo shoot extracts obtained under two different extraction methods.

\begin{tabular}{cccccccc}
\hline Entry & $\begin{array}{c}\text { Extraction } \\
\text { Method }\end{array}$ & Time & TPC $^{\mathbf{a}}$ & TFC $^{\mathbf{b}}$ & DPPH $^{\mathbf{c}}$ & ABTS $^{\mathbf{d}}$ & FRAP $^{\mathbf{d}}$ \\
\hline 1 & Conventional $^{\mathrm{e}}$ & $24 \mathrm{~h}$ & $11.2 \pm 0.1$ & - & - & - & - \\
2 & Conventional $^{\mathrm{f}}$ & $24 \mathrm{~h}$ & $6.6 \pm 0.1$ & $0.81 \pm 0.01$ & 23.33 & $9.1 \pm 0.1$ & $3.22 \pm 0.01$ \\
3 & MAE $^{\mathrm{f}}$ & $4 \mathrm{~min}$ & $54.8 \pm 1.6$ & $1.3 \pm 0.1$ & 9.20 & $71.5 \pm 0.1$ & $62.15 \pm 0.01$ \\
\hline
\end{tabular}

a Total phenolic content, expressed as mg GAE/g dry weight. Values represent means $\pm \mathrm{SD}(n=3) .{ }^{\mathrm{b}}$ Total flavonoid content, expressed as $\mathrm{mg} \mathrm{QE} / \mathrm{g}$ dry weight. Values represent means $\pm \mathrm{SD}(n=3)$. ${ }^{\mathrm{c}} \mathrm{SC}_{50}$ : radical scavenging activity (concentration expressed in $\mu \mathrm{g} / \mathrm{mL}$ necessary for $50 \%$ reduction of DPPH radical). ${ }^{\mathrm{d}}$ expressed as $\mathrm{mg}$ TE/g dry weight. Values represent means $\pm \mathrm{SD}(n=3)$. ${ }^{\text {e }} 50 \mathrm{mg} / 7.5 \mathrm{~mL}$ according to the procedure of Park et al. [5]. f $50 \mathrm{mg} / 2 \mathrm{~mL}$.

On the other hand, our results pave the way for industrial application of bamboo shoots (Phyllostachys pubescens) MAE since our extracts, with high antioxidant content and obtained in a few minutes (thus, reducing energy consumption), could serve as valuable sources of natural antioxidants in the nutraceutical and cosmetic industries. This will be achievable when extractions will be performed with a green solvent (extractions with water or EtOH are under investigation).

\subsection{Total Flavonoid Content}

The total flavonoid content in the bamboo shoot extracts obtained with both extraction methods were also determined and the values obtained are $0.81 \pm 0.01 \mathrm{mg} Q E / g$ dry weight and $1.3 \pm 0.1 \mathrm{mg}$ $\mathrm{QE} / \mathrm{g}$ dry weight in conventional and microwave-assisted extracts, respectively (Table 2). Therefore, microwave irradiation undoubtedly also improves the number of flavonoids extracted from bamboo shoots, which is about twice that obtained by conventional extraction. 


\subsection{Antioxidant Activity of the Extracts Obtained from Bamboo Shoots either by Conventional Extraction or at Optimal MAE Conditions}

Several methods can be employed to evaluate the in vitro antioxidant activity of plant extracts and we chose DPPH, ABTS, and FRAP assays, which are among the most widely used. The results for the extracts obtained with both reflux extraction and MAE at optimal conditions are reported in Table 2.

The obtained results demonstrated that the MAE at the optimal conditions $\left(105{ }^{\circ} \mathrm{C}, 4 \mathrm{~min}\right.$, and $6.25 \mathrm{mg}$ bamboo shoots/mL methanol) showed higher efficiency of antioxidant extraction compared to the conventional extraction method (room temperature, $24 \mathrm{~h}, 25 \mathrm{mg}$ bamboo shoots/mL methanol). In fact, the antioxidant activity observed with the DPPH assay was more than twice higher in the microwave extracts and in both ABTS and FRAP assays of the mg Trolox equivalent (TE)/g dry weight was even 8-20-fold higher in the extracts obtained through the MAE process with respect to the conventional method. These results underline the usefulness of microwave irradiation as an innovative extraction procedure applied to bamboo shoots of Phyllostachys pubescens since it guarantees a higher recovery of an antioxidant compound in extremely reduced times. In fact, the microwave-assisted extraction, which gave the results reported in Table 2, has been performed in only 4 min with a significant reduction in energy consumption and a considerable gain in time.

\subsection{HPLC Analyses}

In order to corroborate our previous observation about the antioxidant capacity, HPLC-DAD analyses of the extracts of bamboo shoots, obtained under optimal conditions, were performed. As depicted in Figure S2, the chromatographic profiles seem to confirm the found TPC and TFC values. The MW extract (A) was richer of polyphenolic compounds, especially those absorbing at $320 \mathrm{~nm}$ (Figure S2b), than a conventional one (B). Polyphenols revealed at $320 \mathrm{~nm}$ generally belongs to the family of hydroxycinnamic acids (i.e., caffeic acid, chlorogenic acid, and $p$-coumaric acid) or flavones (i.e., apigenin and luteolin glycosides), already identified in bamboo extracts [38,39], that are characterized by antioxidant properties [40]. Therefore, the consistent difference in their content between the two extracts (A vs. B) could be related to the higher antioxidant capacity of the MW extract. Anyway, further analyses involving mass spectrometry acquisitions will need to correctly identify and quantify these compounds.

\section{Materials and Methods}

\subsection{Plant Material}

Fresh bamboo shoots (500 g) of P. pubescens were harvested on April 2016 from Ravenna cultivar (Emilia Romagna, Italy) and provided by Consorzio Bamboo Italia. They were collected and kept at $-20{ }^{\circ} \mathrm{C}$ until needed. Leaves were removed and bamboo shoots were sliced and freeze-dried (Christ Alpha 1-4 LSC). Dried bamboo shoots were then finely grinded with mortar and pestle and sifted through mesh strainers (200-500 $\mu \mathrm{m}$, Cecchinato).

\subsection{Chemicals and Reagents}

$\mathrm{MeOH}$ used for extraction, Folin-Ciocalteu reagent, gallic acid, acetic acid, sodium carbonate, quercetin, aluminum chloride $\left(\mathrm{AlCl}_{3}\right)$, sodium-potassium tartrate, 2,2-diphenyl-1-picrylhydrazyl (DPPH), 2,2'-azobis(2-amidinopropane) dihydrochloride (AAPH), 2,4,6-tris(2-pyridyl)-s-triazine 98\%, and 6-hydroxy-2,5,7,8-tetramethyl chromane 2-carboxylic acid (trolox) were purchased from Sigma-Aldrich (Milan, Italy). 2,2'-Azinobis(3-ethylbenzothiazoline-6-sulphonic acid)diammonium salt (ABTS), iron chloride hexahydrate, and sodium acetate trihydrate $99 \%$ were purchased from Alfa Aesar (Karlsruhe, Germany). Formic acid, acetonitrile, and water HPLC grade used for HPLC analyses were purchased from Sigma Aldrich (Milano, Italy). 


\subsection{Conventional Extraction}

A suspension of $50 \mathrm{mg}$ of bamboo shoot powder in the appropriate volume of $\mathrm{MeOH}(7.5$ or $2 \mathrm{~mL}$, entries 1, 2 of Table 2) was stirred at room temperature for $24 \mathrm{~h}$. The solution was then filtered through Whatman (No. 1) filter paper and stored at $-20^{\circ} \mathrm{C}$ until needed for analysis.

\subsection{Microwave-Assisted Extraction (MAE)}

A closed-system MAE was carried out at constant temperature, with continuous stirring, in a CEM Discover Bench Mate microwave reactor equipped with Synergy software. The temperature was measured and controlled by a built-in infrared detector. Briefly, $50 \mathrm{mg}$ of bamboo shoot powder in the appropriate volume of solvent, according to the solid/liquid ratio $(\mathrm{mg} / \mathrm{mL})$ value reported in Table 1 , were irradiated with microwaves $(35 \mathrm{~W})$ at different temperatures for different times (see Table 1 ). The solution was then filtered through Whatman (No. 1) filter paper and stored at $-20{ }^{\circ} \mathrm{C}$ until needed for analysis.

\subsection{Polyphenol Assays}

\subsubsection{Determination of the Total Phenolic Content (TPC)}

The total amount of polyphenols in the prepared extracts was determined according to the method described by Blainski [41], with some modification. The Folin-Ciocalteu reagent was used and a standard calibration curve $\left(\mathrm{R}^{2}=0.9987\right)$ was prepared using different concentrations of gallic acid in methanol (0.025-0.200 mg/mL). Furthermore, $50 \mu \mathrm{L}$ aliquot of each sample, $50 \mu \mathrm{L}$ of Folin-Ciocalteu reagent, $50 \mu \mathrm{L}$ of $\mathrm{MeOH}$, and $250 \mu \mathrm{L}$ of water were mixed. In addition, $200 \mu \mathrm{L}$ of sodium carbonate $(20 \%)$ and $400 \mu \mathrm{L}$ of water were then added and the solution was incubated at $30{ }^{\circ} \mathrm{C}$ for 90 min after which its absorbance was measured against a reagent blank at $700 \mathrm{~nm}$ (Perkin Elmer, Lambda Bio 20, Boston, MA, USA). The assay was performed in triplicate and the final results were expressed as milligrams of a gallic acid equivalent (GAE) per $\mathrm{g}$ of bamboo shoots (mg GAE/g of bamboo shoots).

\subsubsection{Determination of the Total Flavonoids}

The total amount of flavonoids was determined according to the aluminum chloride method described by Khatiwora et al. [42]. A calibration curve $\left(\mathrm{R}^{2}=0.9983\right)$ was prepared using different concentrations of quercetin in methanol $(2.5-18 \mu \mathrm{g} / \mathrm{mL})$. Afterward, $16 \mu \mathrm{L}$ of $\mathrm{AlCl}_{3}(10 \%)$ and $16 \mu \mathrm{L}$ of $\mathrm{Na}^{+} / \mathrm{K}^{+}$tartrate $(10 \%)$ were added to $500 \mu \mathrm{L}$ aliquot of each sample. The solution was then brought to $1 \mathrm{~mL}$ with water and incubated for $30 \mathrm{~min}$. The absorbance was measured at $415 \mathrm{~nm}$ (Perkin Elmer, Lambda Bio 20) against a reagent blank. The assay was performed in triplicate and the results were expressed as $\mathrm{mg}$ of quercetin equivalent (QE) per $\mathrm{g}$ of bamboo shoots (mg QE/g of bamboo).

\subsection{Antioxidant Activity}

\subsubsection{DPPH Assay}

Total free radical scavenging capacity of the extracts using the stable DPPH radical was determined according to the previously reported procedure $[43,44]$, with some modifications. A calibration curve $\left(R^{2}=0.9934\right)$ was prepared using different concentrations of gallic acid in methanol $(0-4 \mu \mathrm{g} / \mathrm{mL})$. In addition, $650 \mu \mathrm{L}$ of each sample were diluted with $350 \mu \mathrm{L}$ of a methanolic solution of a DPPH radical to obtain a final concentration of $100 \mu \mathrm{M}$. The solution was then vigorously mixed and incubated at $30{ }^{\circ} \mathrm{C}$ for $30 \mathrm{~min}$ in the dark. The reduction of DPPH concentration was recorded by a decrease in absorbance at $517 \mathrm{~nm}$ using a UV-vis spectrophotometer (Perkin Elmer, Lambda Bio 20) against a reagent blank and the assay was performed in triplicate. The results were expressed as $\mathrm{SC}_{50}$ values $(\mu \mathrm{g} / \mathrm{mL}$ necessary for $50 \%$ reduction of the DPPH radical), which were calculated with the calibration curve obtained with different concentrations of a sample extract. 


\subsubsection{ABTS Assay}

The antioxidant activity of the extracts using ABTS radical cation decolorization assay was determined, according to the procedure previously reported by Arnao et al. [45], with some modifications. The stock solutions included $7.4 \mathrm{mM} \mathrm{ABTS}^{\bullet+}$ solution and $2.6 \mathrm{mM}$ potassium persulfate solution. The working solution was then prepared by mixing the two stock solutions in equal quantities and allows them to react for $12 \mathrm{~h}$ at room temperature in the dark. The solution was then diluted by mixing $1 \mathrm{~mL} \mathrm{ABTS}^{\bullet+}$ solution with $30 \mathrm{~mL}$ methanol to obtain an absorbance of $1.17 \pm 0.02$ units at $734 \mathrm{~nm}$ using the spectrophotometer. Fresh $\mathrm{ABTS}^{\bullet+}$ solution was prepared for each assay. The standard curve $\left(R^{2}=0.9981\right)$ was linear in the range of 0 to $150 \mu \mathrm{g} / \mathrm{mL}$ Trolox. The extracts $(150 \mathrm{~mL})$ were allowed to react with $2850 \mathrm{~mL}$ of the $\mathrm{ABTS}^{\bullet+}$ solution for $10 \mathrm{~min}$ in a dark condition. Then the absorbance was taken at $734 \mathrm{~nm}$ using the spectrophotometer. Results are expressed in mg Trolox equivalents (TE) per $\mathrm{g}$ of bamboo shoots (mg TE/g bamboo shoots) and were calculated using the following formula.

$$
\text { ABTS radical scavenging activity }=\frac{\text { Absorabnce }_{\text {blank }}-\text { Absorbance }_{\text {sample }}}{\text { Absorbance }_{\text {blank }}} \times 100
$$

Additional dilution was needed if the ABTS value measured was over the linear range of the standard curve.

\subsubsection{FRAP Assay}

The antioxidant capacity of the extracts was measured spectrophotometrically through the FRAP assay following the procedure of Benzie and Strain [46], with some modifications. The stock solution was prepared with $300 \mathrm{mM}$ acetate buffer $\left(3.1 \mathrm{~g} \mathrm{CH}_{3} \mathrm{CO}_{2} \mathrm{Na} \cdot 3 \mathrm{H}_{2} \mathrm{O}\right.$ and $\left.16 \mathrm{~mL} \mathrm{CH} \mathrm{CH}_{3} \mathrm{COOH}\right), 10 \mathrm{mM}$ TPTZ (2,4,6-tripyridyl-s-triazine) solution in $40 \mathrm{mM} \mathrm{HCl}$, and $20 \mathrm{mM} \mathrm{FeCl}_{3} \cdot 6 \mathrm{H}_{2} \mathrm{O}$ solution. The fresh working solution was prepared by mixing $25 \mathrm{~mL}$ of acetate buffer, $2.5 \mathrm{~mL}$ of TPTZ solution, and $2.5 \mathrm{~mL}$ of $\mathrm{FeCl}_{3} \cdot 6 \mathrm{H}_{2} \mathrm{O}$ solution, and then warmed at $37^{\circ} \mathrm{C}$ before using. The extracts $(150 \mu \mathrm{L})$ were allowed to react with $2850 \mu \mathrm{L}$ of the FRAP solution for $30 \mathrm{~min}$ in the dark condition. Readings of the colored product [ferrous tripyridyltriazine complex] were then measured at $593 \mathrm{~nm}$. The standard curve $\left(R^{2}=0.9962\right)$ was linear in the range $0-200 \mu \mathrm{g} / \mathrm{mL}$ Trolox. Results are expressed in $\mathrm{mg} T \mathrm{TE} / \mathrm{g}$ dry weight. Additional dilution was needed if the FRAP value measured was over the linear range of the standard curve.

\subsection{Experimental Design for Microwave Extraction Optimization (RSM)}

The extraction parameters were optimized using response surface methodology. A central composite face-centered design (CCF) was employed to evaluate the effects of three independent parameters [extraction temperature $\left(X_{1}\right)$, solid/liquid ratio $\left(X_{2}\right)$, and extraction time $\left(X_{3}\right)$ ] on the response variable (TPC), as shown in Table 1 . The values of the three independent variables reported in Table 1 were based on the results of preliminary experiments (data not shown). Seventeen experiments were conducted, with three replications at the center values to evaluate the pure error sum of squares. Experimental data were fitted with the quadratic model shown below (Equation (2)).

$$
Y=b_{0}+\sum b_{i} X_{i}+\sum b_{i i} X_{i}^{2}+\sum b_{i j} X_{i} X_{j}
$$

where $Y$ is the dependent parameter (TPC), $X_{i}$ and $X_{j}$ are the independent variables $\left(X_{1}-X_{3}\right), b_{0}$ is the intercept, and $b_{i}, b_{i i}$, and $b_{i j}$ are the linear, quadratic, and interaction coefficients, respectively. The model prediction capability is commonly explained by the coefficient of determination $\left(R^{2}\right)$. The analysis of variances (ANOVA) was also used to evaluate the quality of the fitted model. The test of statistical difference was based on the total error criterion with a confidence level of $95 \%$. Analysis of the experimental design data and calculation of predicted responses were carried out using the commercial Modde 6.0 software (Umetrics, Malmo, Sweden). 


\subsection{HPLC-DAD Analyses}

HPLC-DAD analysis was performed by an HPLC 1100 (Agilent Technologies, Palo Alto, CA, USA) equipped with a degasser, quaternary pump solvent delivery, thermo-stated column compartment, and a diode array detector. Chromatographic separation was performed by using Zorbax SB C18 $3.5 \mu \mathrm{m}(150 \times 4.6 \mathrm{~mm}$ i.d., Agilent Technologies $)$ with a pre-column Gemini C18 $5 \mu \mathrm{m}(4 \times 2 \mathrm{~mm}$ i.d., Phenomenex) as reversed stationary phase, and a binary solvent system (solvent A: $1 \%$ formic acid in water, solvent $\mathrm{B}$ : acetonitrile) as a mobile phase. The following gradient elution program was used: 0-1.5 $\mathrm{min}, 2 \% \mathrm{~B}, 1.5-3 \mathrm{~min}, 2-9 \% \mathrm{~B}, 3-6 \mathrm{~min}, 9-14 \% \mathrm{~B}, 6-7 \mathrm{~min}, 14-19 \% \mathrm{~B}, 7-8 \mathrm{~min}$ held at $19 \%$ B , 8-15 min, $19-27 \%$ B, 15-25 min, 27-37\% B, 25-30 min, 37-90\% B, 30-32 min, held at $90 \%$ B, $32-33 \mathrm{~min}, 90-2 \% \mathrm{~B}$, held for $5 \mathrm{~min}$ at $2 \% \mathrm{~B}$ to re-equilibrate the column. Flow rate, column temperature, and injection volume were set up at $1.0 \mathrm{~mL} \mathrm{~min}^{-1}, 40{ }^{\circ} \mathrm{C}$, and $3 \mu \mathrm{L}$. Diode array detection was between 250 and $600 \mathrm{~nm}$, and absorbances were recorded at 280 and $320 \mathrm{~nm}$.

\section{Conclusions}

In this study, response surface methodology has been applied to optimize the TPC in bamboo shoot (P. pubescens) extracts obtained by MAE. Influencing parameters on the extraction yield of polyphenols were studied and the optimal found MAE conditions predicted by the quadratic model generated by RSM design were solid/liquid ratio of $6.25: 1(\mathrm{mg} / \mathrm{mL})$, microwave extraction temperature of $105^{\circ} \mathrm{C}$, and microwave extraction time of $4 \mathrm{~min}$ that gave $54.8 \pm 1.6 \mathrm{mg}$ GAE/g dry weight as TPC content. This result demonstrates the usefulness of microwave irradiation for the polyphenol extraction from bamboo shoots since the TPC value obtained with microwave irradiation was about eight-fold higher than that obtained with the conventional extraction. Although a conventional extraction has not been carried out at the same temperature, which would have been necessary to compare the effects of conductive and dielectric heating, it can be stated that the use of microwaves guaranteed at least a drastic reduction in extraction time (to only $4 \mathrm{~min}$ ). Thus, at the laboratory scale, MAE performs as a powerful method for increasing extraction efficiency of antioxidant compounds from bamboo shoots of $P$. pubescens reducing time and energy consumption. On the other hand, the scale-up of our method is necessary to ensure the economical industry production of the highest quality extracts from bamboo shoots, which faces the ever-increasing need for natural anti-oxidant agents.

Supplementary Materials: The following are available online at http://www.mdpi.com/1420-3049/25/1/215/s1, Table S1: Screening of parameters influencing microwave-assisted extraction of bamboo shoots: design matrix and observed responses; Figure S1: Response surface plot of the effect of extraction temperature and solid/liquid ratio on polyphenol yield (TPC) obtained through MAE; Figure S2: HPLC-DAD chromatograms recorded at a) $280 \mathrm{~nm}$ and b) $320 \mathrm{~nm}$ of the bamboo shoots MW extract obtained under optimal conditions (A) and conventional extract (B), respectively.

Author Contributions: M.M.C. conceived, designed the experiments, and wrote the paper. G.M. and F.C (Francesca Curci). performed the experiments. P.C. performed HPLC analyses. I.P. supervised to the antioxidant tests. F.C (Filomena Corbo) and C.F. supervised the project. G.L. and M.L.C. edited the paper. All authors have read and agreed to the published version of the manuscript.

Funding: The Ricerca Globale Istituto di Ricerche Cliniche e Biomediche-Tecnopolis-Parco Scientifico Tecnologico-Valenzano Bari and by Consorzio Bamboo Italia srl supported the work financially.

Conflicts of Interest: The authors declare no conflict of interest.

\section{References}

1. Satya, S.; Bal, L.M.; Singhal, P.; Naik, S.N. Bamboo shoot processing: Food quality and safety aspect (a review). Trends Food Sci. Technol. 2010, 21, 181-189. [CrossRef]

2. Sangeetha, R.; Diea, Y.K.T.; Chaitra, C.; Malvi, P.G.; Shinomol. G.K. The Amazing Bamboo: A Review on its Medicinal and Pharmacological Potential. Indian J. Nutr. 2015, 2, 106.

3. Nirmala, C.; Madho, S.B.; Sheena, H. Nutritional properties of bamboo shoots: Potential and prospects for utilization as a health food. Compr. Rev. Food Sci. Food Saf. 2011, 10, 153-169. 
4. Tanaka, A.; Zhu, Q.; Tan, H.; Horiba, H.; Ohnuki, K.; Mori, Y.; Yamauchi, R.; Ishikawa, H.; Iwamoto, A.; Kawahara, H.; et al. Biological activities and phytochemical profiles of extracts from different parts of bamboo (Phyllostachys pubescens). Molecules 2014, 19, 8238-8260. [CrossRef] [PubMed]

5. Park, E.-J.; Jhon, D.-Y. The antioxidant, angiotensin converting enzyme inhibition activity, and phenolic compounds of bamboo shoot extracts. LWT Food Sci. Technol. 2010, 43, 655-659. [CrossRef]

6. Sun, Y.; Yang, K.; Cao, Q.; Sun, J.; Xia, Y.; Wang, Y.; Li, W.; Ma, C.; Liu, S. Homogenate-assisted vacuum-powered bubble extraction of moso bamboo flavonoids for on-line scavenging free radical capacity analysis. Molecules 2017, 22, 1156. [CrossRef]

7. Koide, C.L.K.; Collier, A.C.; Berry, M.J.; Panee, J. The effect of bamboo extract on hepatic biotransforming enzymes-Findings from an obese-diabetic mouse model. J. Ethnopharmacol. 2011, 133, 37-45. [CrossRef]

8. Panee, J.; Liu, W.; Lin, Y.; Gilman, C.; Berry, M.J. A novel function of bamboo extract in relieving lipotoxicity. Phytother. Res. 2008, 22, 675-680. [CrossRef]

9. Kuboyama, N.; Fujii, A.; Tamura, T. Antitumor activities of bamboo leaf extracts (BLE) and its lignin (BLL). Folia Pharmacol. JPN 1981, 77, 579-596. [CrossRef]

10. Jin, Y.-C.; Yuan, K.; Zhang, J. Chemical composition, and antioxidant and antimicrobial activities of essential oil of Phyllostachys heterocycla cv. Pubescens varieties from China. Molecules 2011, 16, 4318-4327.

11. Hu, C.; Zhang, Y.; Kitts, D. Evaluation of antioxidant and prooxidant activities of Bamboo Phyllostachys nigra var. Henonis leaf extract in vitro. J. Agric. Food Chem. 2000, 48, 3170-3176. [CrossRef] [PubMed]

12. Kweon, M.-H.; Hwang, H.-J.; Sung, H.-C. Identification and antioxidant activity of novel chlorogenic acid derivatives from Bamboo (Phyllostachys edulis). J. Agric. Food Chem. 2001, 49, 4646-4655. [CrossRef] [PubMed]

13. Mulyono, N.; Lay, B.W.; Rahayu, S.; Yaprianti, I. Antibacterial activity of Petung Bamboo (Dendrocalamus Asper) leaf extract against pathogenic Escherichia coli and their chemical identification. Int. J. Pharm. Biol. 2012, 3, 770-778.

14. Wang, J.; Yue, Y.-D.; Tang, F.; Sun, J. TLC screening for antioxidant activity of extracts from fifteen Bamboo species and identification of antioxidant flavone glycosides from leaves of Bambusa. textilis McClure. Molecules 2012, 17, 12297-12311. [CrossRef] [PubMed]

15. Yasin, S.; Liu, L.; Yao, J. Biosynthesis of silver nanoparticles by Bamboo leaves extract and their antimicrobial activity. J. Fiber Bioeng. Inf. 2013, 6, 77-84.

16. Shang, Y.F.; Kim, S.M.; Um, B.-H. Optimisation of pressurised liquid extraction of antioxidants from black bamboo leaves. Food Chem. 2014, 154, 164-170. [CrossRef]

17. Nongdam, P.; Tikendra, L. The nutritional facts of bamboo shoots and their usage as important traditional foods of northeast India. Int. Sch. Res. 2014, 2014, 679073. [CrossRef]

18. Kalita, C.; Ganguly, M.; Devi, A. Evaluation of antioxidant capacity and antimicrobial properties of ethnic bambuseae species and identification of the active components. Int. J. Pharm. Biol. Arch. 2016, 7, 61-71.

19. Nirmala, C.; Bisht, M.S.; Laishram, M. Bioactive compounds in bamboo shoots: Health benefits and prospects for developing functional foods. Int. J. Food Sci. Technol. 2014, 49, 1425-1431. [CrossRef]

20. Kris-Etherton, P.M.; Hecker, K.D.; Bonanome, A.; Coval, S.M.; Binkoski, A.E.; Hilpert, K.F.; Griel, A.E.; Etherton, T.D. Bioactive compounds in foods: Their role in the prevention of cardiovascular disease and cancer. Am. J. Med. 2002, 113, 71S-88S. [CrossRef]

21. Ren, Y.; Ma, Y.; Zhang, Z.; Qiu, L.; Zhai, H.; Gu, R.; Xie, Y. Total alkaloids from bamboo shoots and bamboo shoot shells of Pleioblastus amarus (Keng) Keng f. and their anti-inflammatory activities. Molecules 2019, 24, 2699. [CrossRef] [PubMed]

22. Zhang, Z.; Wang, X.; Yu, S.; Zhao, M. Isolation and antioxidant activities of polysaccharides extracted from the shoots of Phyllostachys edulis (Carr.). Int. J. Biol. Macromol. 2011, 49, 454-457. [CrossRef] [PubMed]

23. Li, Y.-X.; Cheng, F.-R.; Jin, Y.-C.; Yuan, K. Studies on the active components and antioxidant activity of the extracts from different parts of Bamboo. Asian J. Chem. 2013, 25, 6354-6360. [CrossRef]

24. Cory, H.; Passarelli, S.; Szeto, J.; Tamez, M.; Mattei, J. The Role of Polyphenols in Human Health and Food Systems: A mini-Review. Front. Nutr. 2018, 5, 87. [CrossRef]

25. Caleja, C.; Ribeiro, A.; Barreiro, M.F.; Ferreira, I.C.F.R. Phenolic compounds as nutraceuticals or functional food ingredients. Curr. Pharm. Des. 2017, 23, 2787-2806. [CrossRef]

26. Clark, L.G.; Londoño, X.; Ruiz-Sanchez, E. Bamboo Taxonomy and Habitat. In Bamboo; Liese, W., Köhl, M., Eds.; Springer: Cham, Switzerland, 2015; Chapter 1. 
27. Zhang, Q.-W.; Lin, L.-G.; Ye, W.-C. Techniques for extraction and isolation of natural products: A comprehensive review. Chin. Med. 2018, 13, 20. [CrossRef]

28. Sahin, S.; Samli, R.; Tan, A.S.B.; Barba, F.J.; Chemat, F.; Cravotto, G.; Lorenzo, J.M. Solvent-free microwave-assisted extraction of polyphenols from olive tree leaves: Antioxidant and antimicrobial properties. Molecules 2017, 22, 1056. [CrossRef]

29. Microwave-Assisted Extraction for Bioactive Compounds: Theory and Practice; XII, Series: Food Engineering Series; Springer Science: New York, NY, USA, 2013; p. 238.

30. Cova, C.M.; Boffa, L.; Pistocchi, M.; Giorgini, S.; Luque, R.; Cravotto, G. Technology and process design for phenols recovery from industrial Chicory (Chicorium intybus) leftovers. Molecules 2019, 24, 2681. [CrossRef]

31. Zhang, L.; Wang, Y.; Wu, D.; Xu, M.; Chen, J. Microwave-assisted extraction of polyphenols from Camellia oleifera fruit hull. Molecules 2011, 16, 4428-4437. [CrossRef]

32. Roselli, M.; Lovece, A.; Bruno, C.; Cavalluzzi, M.M.; Laghezza, A.; Mercurio, A.; Lentini, G.; Corbo, F.; La Forgia, F.; Fontana, S.; et al. Antioxidant activity of Uva di Troia Canosina: Comparison of two extraction methods. Clin. Immunol. Endocr. Metab. Drugs 2015, 2, 8-12. [CrossRef]

33. Lovrić, V.; Putnik, P.; Kovačević, D.B.; Jukić, M.; Dragović-Uzelac, V. Effect of microwave-assisted extraction on the phenolic compounds and antioxidant capacity of blackthorn flowers. Food Technol. Biotechnol. 2017, 55, 243-250. [CrossRef] [PubMed]

34. Zhu, X.; Su, Q.; Cai, J.; Yang, J. Optimization of microwave assisted solvent extraction for volatile organic acids in tobacco and its comparison with conventional extraction methods. Anal. Chim. Acta 2006, 579, 88-94. [CrossRef] [PubMed]

35. Wang, L.; Weller, C.L. Recent advances in extraction of nutraceuticals from plants. Trends Food Sci. Technol. 2006, 17, 300-312. [CrossRef]

36. Mandal, V.; Mohan, Y.; Hemalatha, S. Microwave assisted extraction-An innovative and promising extraction tool for medicinal plant research. Pharmacogn. Rev. 2007, 1, 7-18.

37. Eskilsson, C.S.; Björklund, E. Analytical-scale microwave-assisted extraction. J. Chromatogr. A 2000, 902, 227-250. [CrossRef]

38. Van Hoyweghen, L.; De Beer, T.; Deforce, D.; Heyerick, A. Phenolic compounds and anti-oxidant capacity of twelve morphologically heterogeneous Bamboo species. Phytochem. Anal. 2012, 23, 433-443. [CrossRef]

39. Liu, M.H.; Ko, C.-H.; Ma, N.; Tan, P.-W.; Fu, W.-M.; He, J.-Y. Chemical profiles, antioxidant and anti-obesity effects of extract of Bambusa textilis McClure leaves. J. Funct. Foods 2016, 22, 533-546. [CrossRef]

40. Dai, J.; Mumper, R.J. Plant phenolics: Extraction, analysis and their antioxidant and anticancer properties. Molucules 2010, 15, 7313-7352. [CrossRef]

41. Blainski, A.; Lopes, G.C.; Palazzo de Mello, J.C. Application and analysis of the Folin Ciocalteu method for the determination of the total phenolic content from Limonium Brasiliense, L. Molecules 2013, 18, 6852-6865. [CrossRef]

42. Khatiwora, E.; Adsul, V.B.; Kulkarni, M.M.; Deshpande, N.R.; Kashalkar, R.V. Spectroscopic determination of total phenol and flavonoid contents of Ipomoea carnea. Int. J. Chem.Tech. Res. 2010, 2, 1698-1701.

43. Roselli, M.G.; Cavalluzzi, M.M.; Bruno, C.; Lovece, A.; Carocci, A.; Franchini, C.; Habtemariam, S.; Lentini, G. Synthesis and evaluation of berberine derivatives and analogs as potential antiacetylcholinesterase and antioxidant agents. Phytochem. Lett. 2016, 18, 150-156. [CrossRef]

44. Clodoveo, M.L.; Dipalmo, T.; Crupi, P.; Durante, V.; Pesce, V.; Maiellaro, I.; Lovece, A.; Mercurio, A.; Laghezza, A.; Corbo, F.; et al. Comparison between different flavored olive oil production techniques: Healthy value and process efficiency. Plant. Food Hum. Nutr. 2016, 71, 81-87. [CrossRef] [PubMed]

45. Arnao, M.B.; Cano, A.; Acosta, M. The hydrophilic and lipophilic contribution to total antioxidant activity. Food Chem. 2001, 73, 239-244. [CrossRef]

46. Benzie, I.F.F.; Strain, J.J. The ferric reducing ability of plasma (FRAP) as a measure of "antioxidant power": The FRAP assay. Anal. Biochem. 1996, 239, 70-76. [CrossRef] [PubMed]

Sample Availability: Samples of the compounds are not available from the authors.

(C) 2020 by the authors. Licensee MDPI, Basel, Switzerland. This article is an open access article distributed under the terms and conditions of the Creative Commons Attribution (CC BY) license (http://creativecommons.org/licenses/by/4.0/). 